\title{
Minimally invasive robotic breast reconstruction surgery
}

\author{
Sarah N. Bishop, Jesse C. Selber \\ Department of Plastic Surgery, MD Anderson Cancer Center, Houston, TX, USA \\ Contributions: (I) Conception and design: JC Selber; (II) Administrative support: None; (III) Provision of study materials or patients: JC Selber; (IV) \\ Collection and assembly of data: JC Selber; (V) Data analysis and interpretation: JC Selber; (VI) Manuscript writing: All authors; (VII) Final approval \\ of manuscript: All authors. \\ Correspondence to: Jesse C. Selber, MD, MPH, FACS. Professor, Director of Clinical Research, Department of Plastic Surgery, MD Anderson Cancer \\ Center, Houston, TX 77030, USA. Email: jcselber@mdanderson.org.
}

\begin{abstract}
The rising popularity of robotic surgery has enabled surgeons to continue to expand the uses of robotic surgery. Robotic surgery offers minimally invasive approaches coupled with tremor elimination, up to seven degrees of freedom, ergonomic positioning, 3D magnified vision and improved resolution. We describe robotic surgery techniques for nipple-sparing mastectomies, latissimus dorsi muscle flap harvest, deep inferior epigastric perforator (DIEP) flap pedicle harvest, and robotic microsurgical anastomoses. By using a robotic system the surgeon is able to offer not only a minimally invasive approach to the patient but the surgeon's ability can be improved upon as well. This improved ability is best characterized in the robotic supermicrosurgical anastomosis where even the faintest surgeon's tremor is exploited. However, within the robotic system tremor is eliminated. We are now able to offer patients a completely minimally invasive approach to ablative breast surgery and breast reconstruction. A patient could have a robotic nipple-sparing mastectomy, followed by a robotic DIEP reconstruction with a robotic microsurgical anastomosis. The patient could even have robotic lymphovenous bypass to address lymphedema that could have arisen after an axillary dissection. A completely robotic surgical approach maximizes both utilization of the robotic system and patient benefit. By using robotic techniques in flap harvest the morbidity of traditional open surgeries is minimized and the use of robotic anastomoses expands the limits of human precision.
\end{abstract}

Keywords: Robotic deep inferior epigastric perforator (robotic DIEP); robotic latissimus; robotic microsurgery; robotic nipple-sparing mastectomy; minimally invasive breast surgery; robotic breast surgery

Submitted Feb 21, 2020. Accepted for publication Aug 06, 2020.

doi: $10.21037 / \mathrm{gs}-20-248$

View this article at: http://dx.doi.org/10.21037/gs-20-248

\section{Introduction}

The advent of robotic surgery has enabled a new spectrum of minimally invasive breast reconstruction. Minimally invasive breast surgery can enable improved visualization and decreased morbidity for the patient. We now have the ability to offer robotic minimally invasive surgery from the mastectomy to the harvesting of the breast reconstruction to the actual microsurgery-essentially each part of the extirpation and reconstruction.

\section{Robotic surgery}

The concept of using robots to operate remotely was first postulated by the US Army and the National Aeronautics and Space Administration (NASA) (1). Robotic surgery has been able to expand the human limits of surgical technique by offering tremor elimination, up to seven degrees of freedom, ergonomic positioning, 3D magnified vision and improved resolution. The ability to refine human movements and offer minimally invasive techniques has led 
to the use of robotic surgery routinely in many specialties. The first use of robotic surgery was in 1985 with the Programmable Universal Machine for Assembly 200 (PUMA) that was used for a delicate and exact stereotactic neurosurgical biopsy $(2,3)$. This success led Davies to use the Puma 560 to perform a transurethral resection of the prostate (4). Several more iterations of robotic platforms ensued including Surgeon-Assisted Robot for Prostatectomy (SARP), Prostate Robot (PROBOT) and the UROBOT $(2,4)$. These robotic systems worked via the use of fixed anatomical landmarks and were therefore not adaptable to surgeries requiring dynamic ability such as in most general and plastic surgery procedures (2). Again, several different robotic systems were developed to enable dynamic surgery but ultimately the Da Vinci System (Intuitive Surgical Inc., Mountain View, CA) has come to dominate robotic surgery (5). The Da Vinci system works via an "operator-effector" arrangement where the surgeon operates at a console that remotely controls the robotic system positioned at the patient. The improved freedom, dexterity and visualization of the robotic system have led to the dominance of robotic systems use in tight spaces such as in pelvic surgery $(6,7)$. The precision and minimally invasive capabilities has led other surgical fields in general surgery, gynecological surgery, head and neck surgery, plastic surgery and even microsurgery to enhance surgical capabilities through robotic systems (8).

\section{Robotic nipple sparing mastectomy}

Throughout the majority of the $20^{\text {th }}$ century breast cancer was treated with a radical mastectomy as described by Halsted. The radical mastectomy not only eliminated all of the breast tissue and axillary nodal tissue but the chest wall musculature and overlying skin. After a radical mastectomy patients healed by secondary intention or skin grafting and were left with a deformed and sunken chest wall deformity. It was not until 1972 that Madden published on the use of a modified radical mastectomy which spared the chest wall muscles and enough skin to typically enable primary closure (9). The modified radical mastectomy has decreased morbidity by saving the chest wall muscles but the majority of the breast skin and nipple areolar complex are removed. The use of skin-sparing and nipple-sparing mastectomies has greatly improved the aesthetic appearance while still maintaining oncologic outcomes (10). The skin-sparing mastectomy was first described by Toth and Lappert, whereby the skin envelope and breast pocket were preserved. Numerous studies were conducted proving the safety of skin-sparing mastectomies showing that local rates of recurrence were comparable in skin-sparing mastectomies versus non-skin-sparing mastectomies (11-13). By preserving the skin envelope and the breast pocket a more natural breast contour is able to be established and improved scars are able to be aesthetically placed. The nipple-sparing mastectomy improves upon the skin-sparing mastectomy as the nipple areolar complex is able to be saved. The breast tissue and nipple areolar ducts are removed. A frozen section is usually sent of subareolar tissue to confirm negative margins. Atypia or positive surgical margins leads to conversion to a skinsparing mastectomy which ranges from $2.5-12 \%(14,15)$. Fortunately, nipple-sparing mastectomies have not shown a statistically significant difference in disease-free survival, overall survival, or local recurrence rates when compared to either skin-sparing or modified radical mastectomies (16-18). Furthermore, the aesthetics that are obtained in nipple-sparing mastectomies has led to high surgeon and patient satisfaction $(19,20)$.

There are several incisions that can be used for nipplesparing mastectomies including; periareolar, radial, inframammary fold, vertical and wise pattern incisions. Incisions are typically chosen based on the preference of the oncologic surgeons' ability to remove the tumor and comfort level combined with the reconstructive surgeons' preference for improved aesthetics. Many ablative surgeons prefer the periareolar incision as this is similar to the skinsparing mastectomy incision and tumors in this location may be more easily removed for the ablative surgeon. Usually a lateral extension is added to enable adequate exposure. Via the periareolar incision a modest amount of nipple areolar complex repositioning is possible; however, nipple areolar complex necrosis rates are increased if the incision covers more than $30 \%$ of the areolar circumference $(21,22)$. Inframammary fold incisions are most often preferred by reconstructive surgeons as the scar is the most hidden and has lower rates of necrosis than periareolar incisions $(22,23)$. Wise pattern incisions can be performed to enable improved aesthetic outcomes in patients with significant ptosis. Some ablative surgeons may not feel comfortable working via the inframammary incision and they may perform lateral, radial or vertical incisions. The blood supply can safely be maintained, but the subsequent scar is placed in a more obvious area and cicatricial contraction can lead to undesirable nipple areolar complex distortion. 
More patients are becoming candidates for nipplesparing mastectomies as the oncologic criteria has continued to be expanded (15). Even though oncologic surgeons have continued to improve their techniques there are still technical obstacles. To provide the optimal exposure and appropriate tension to enable removal of the breast parenchyma through one incision a significant amount of retraction on the mastectomy flap is needed. This retraction can lead to injury and malperfusion of the mastectomy flaps. Better visualization has been obtainable in other surgical fields by the use of minimally invasive techniques. It was previously felt that a cavity must be present for endoscopic and robotic surgeries; however, refinements in technique have led to the development of robotic surgery in head and neck surgeries $(24,25)$.

Endoscopic nipple-sparing mastectomies have proven feasible and with greater patient satisfaction (26). Furthermore, endoscopic techniques have been validated oncologically in clinical trials $(26,27)$. However, using rigid endoscopic instruments with a two-dimensional endoscopic camera is highly technically challenging and has thus not led to the popularity of this technique (26-31). Using robotic surgery in nipple-sparing mastectomies can enable enhanced exposure which allows for improved preservation of the vasculature to the mastectomy flap. The insufflation provided by robotic surgery replaces the need for retraction which decreases the subsequent damage caused by aggressive retraction on the mastectomy flap.

The robotic assisted nipple-sparing mastectomy (RNSM) was first described by Toesca et al. in 2015 where a nipple-sparing mastectomy from a single axillary scar was performed along with an immediate robotically placed implant for reconstruction (30). Sarfati et al. also published in 2016 showing technical feasibility through a cadaveric study with small incisions using the Da Vinci robotic system (31). Toesca et al. further published a case series of 29 nipple sparing mastectomies and immediate implantbased reconstruction that was able to be completed in approximately 3 hours, with a low conversion to open rate of $6.9 \%$ and no major complications (32). The learning curve was rapid and generally required 5 cases to obtain an average time of 3 hours. The techniques described show incisions approximately $3-4 \mathrm{~cm}$ and insufflation pressures of 7-8 mmHg (30-32). Hypercarbic injuries are prevented by intermittently evacuating $\mathrm{CO} 2$ and placing wet cold gauze over the mastectomy flaps (33). In order to enable safe and efficient robotic nipple sparing mastectomies it is vital for the operating staff to be trained in robotic surgery (34).
Oncologic and aesthetic outcomes have greatly improved which has led to increases in mastectomy rates. A 36\% increase in mastectomy rates was shown between 2005-2013 and double mastectomy rates have tripled (35). The increase in mastectomy rates is seen despite advances in breastconserving therapy (36). Patients want the best oncologic result with improved aesthetics and a minimally invasive approach. With robotic surgery we can now provide this to our patients.

RNSM is currently not approved by the FDA. We are therefore engaged in a multi-center Investigational Device Trial in an effort to achieve $510 \mathrm{k}$ approval from the FDA for the specific indication of nipple sparing mastectomy using the robot.

\section{Robotic latissimus dorsi breast reconstruction}

The latissimus dorsi flap was first described by Iginio Tansini in 1906 and has since been a workhorse flap in the plastic surgeons armamentarium (37). A robust incision between $15-45 \mathrm{~cm}$ in length is used. To enable a less aggressive incision endoscopic techniques have been tried $(38,39)$. However, endoscopic techniques are technically challenging at best and most surgeons have moved away from these techniques $(40,41)$. Selber first described through a cadaveric feasibility study a robotic harvest of a latissimus dorsi muscle (42). Selber et al. followed up with a case series on 7 patients that underwent robotic latissimus dorsi muscle harvest (43). Five of the patients had pedicled breast reconstruction while the remaining two had free flaps for scalp reconstruction. There were no major complications and robotic harvest time decreased from two hours to one hour by the end of the study.

\section{Operative technique}

Patient positioning for the robotic harvest is the same as for the open approach with a decubitus position preferred. The borders of the latissimus dorsi muscle should be marked out to determine proper port placement. An axillary incision is made to facilitate pedicle dissection and port placements. If reconstruction is being performed at the same time as a sentinel lymph node biopsy or an axillary lymph node dissection then the pedicle dissection and port placements can be performed through those incisions. From the axillary incision a long-tip electrocautery and lighted retractors are used to dissect the subcutaneous space superficial to the latissimus muscle. Three subcutaneous ports are placed. 
The first port is placed through the axillary incision where a $12 \mathrm{~mm}$ camera port is placed. A second $5 \mathrm{~mm}$ port is placed $8 \mathrm{~cm}$ distal to the axillary port and $8 \mathrm{~cm}$ anterior to the anterior border of the muscle. The final $8 \mathrm{~mm}$ port is placed $8 \mathrm{~cm}$ distal to the second port and $8 \mathrm{~cm}$ anterior to the anterior border of the muscle. The robotic side cart is placed posterior to the patient with the arms aligned with the plane of the muscle and parallel to the floor (Figure 1). After the arms are docked the insufflation is set to $10 \mathrm{mmHg}$. The dissection is started deep to the muscle to enable the insufflation to help with the dissection. If the dissection were started on the superficial surface first the insufflation would press down on the muscle when the deep surface was subsequently dissected. Dissection is completed with monopolar scissors and a grasper and the vessels are clipped with laparoscopic or robotic clip appliers. After the deep surface is dissected the superficial surface is dissected similarly and the muscle is disinserted from

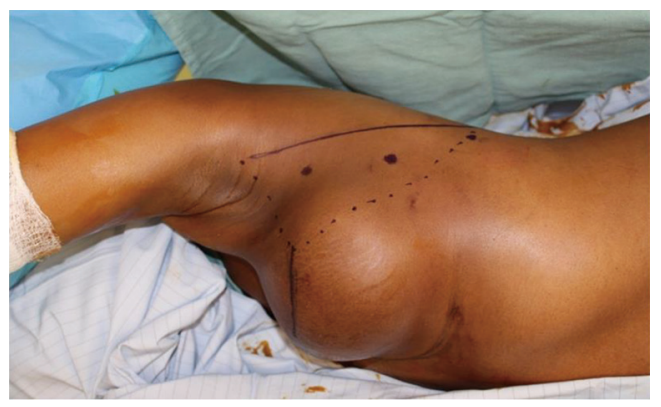

Figure 1 Intended port sites are marked with circles. the inferoposterior border. At the superior and inferior extremes of the muscle the positioning of the robotic arms may subtly conflict and positioning may need to be changed slightly. The patients' ipsilateral arm can also be adjusted to help account for positioning issues. The final dissection should end in the axilla near the pedicle and care should be taken not to injure the blood supply. The robot is now undocked and the axillary incision is opened to complete the pedicle dissection and division of the tendinous insertion. The muscle can now be transferred as a free flap or as a pedicled flap.

For patients that require a muscle only latissimus for breast reconstruction or for other reconstructive needs the robotic approach offers a minimally invasive technique that is reliable and safe (Figure 2).

\section{Robotic DIEP}

The deep inferior epigastric perforator (DIEP) flap has become the enduring gold standard in breast reconstruction. Patients in the long-term are most satisfied with autologous-based breast reconstruction (44-51). Initial breast reconstruction with abdominal based tissue relied on the pedicled and then free Transverse Rectus Abdominis Myocutaneous (TRAM) flap (52,53). Unfortunately, both pedicled and free TRAM flaps sacrifice all of the rectus muscle leading to significant abdominal wall morbidity. The muscle-sparing TRAM was developed to decrease abdominal wall morbidity and is classified according to how much muscle is spared (54). The DIEP flap which
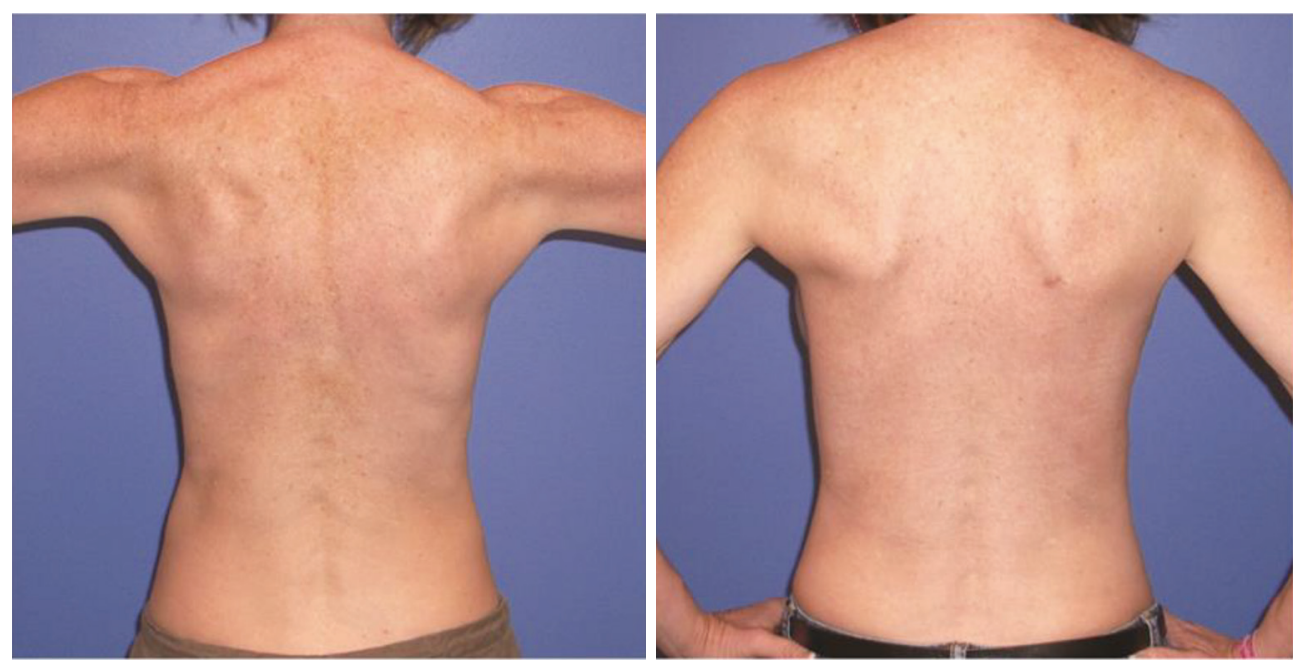

Figure 2 Then donor site scar of a patient after right robotic-assisted latissimus dorsi harvest. 


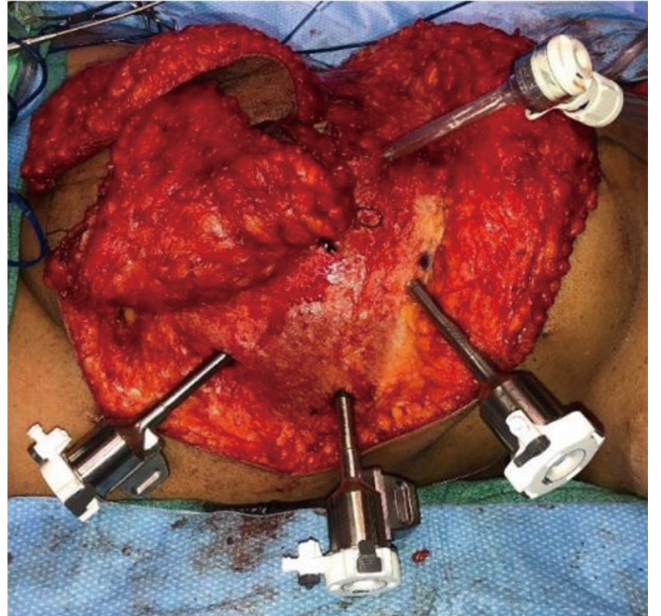

Figure 3 Port placements for the RoboDIEP. The patient's head is to the right.

spares all of the muscle was first described by Koshima and Soeda in 1989 but was subsequently popularized by Allen and Blondeel (55-57). Decreasing the amount of muscle sacrificed has shown to decrease the abdominal wall morbidity (58). However, even with DIEPs muscle bulging can occur with damage to the segmental rectus nerves; therefore, preservation of nerves is important in decreasing muscle bulging (59). Unfortunately, even with refinements in technique a large fascial incision is necessary when approaching through the traditional open anterior approach. The DIEP pedicle runs along the deep surface of the rectus muscle; therefore, when dissecting the muscle typically needs to be split which leads to direct damage to the muscle and often sacrifice of the neurovascular bundles to the rectus muscle leading to defunctionalized muscle and subsequent bulging. A large fascial incision and muscle splitting will most certainly lead to increased postoperative pain in the short term and increased hernia and muscle bulge rates in the medium and long term.

By approaching the pedicle dissection posteriorly the fascial incision can be greatly minimized. By using a robotic system a posterior harvest can be facilitated. To determine which patients are best candidates for a robotic approach preoperative imaging with a computed tomography angiogram (CTA) is critical. Many surgeons also use CTA for the traditional approach as CTA has shown to improve outcomes and decrease operating times $(60,61)$. A patient with a single perforator or two closely grouped perforators with a short intramuscular course is the optimal candidate for a robotic approach. If many perforators are required to perfuse the DIEP flap then more anterior dissection is needed leading to a larger fascial incision and thus less benefit from the robotic approach.

A mathematical equation can be used to determine if a benefit will be obtained from the posterior robotic approach. The equation $\mathrm{B}=\mathrm{C}-\mathrm{A}$, where $\mathrm{B}$ is the Benefit or the reduced fascial length. $\mathrm{C}$ is the entire length of the pedicle from the perforator to its origin at the external iliac vessels. A is the intramuscular course measured on the preoperative CTA. For example if the pedicle length $\mathrm{C}$ is $13.5 \mathrm{~cm}$ and the intramuscular course A is $3.5 \mathrm{~cm}$ then the Benefit is $10.5 \mathrm{~cm}$. A reduction of $10.5 \mathrm{~cm}$ in fascial length is certainly significant.

\section{Operative technique}

The operative technique for the robotic DIEP begins as in the open fashion with elevation of the abdominal flaps. The pre-selected perforator chosen from pre-operative imaging is exposed and dissected to the deep surface of the rectus muscle. In the open version the fascial incision is extended to be able to dissect out the pedicle. However, in the robotic version the pedicle dissection will be approached posteriorly within the intraperitoneal cavity and therefore the fascial incision is only needed to dissect out the perforator. The fascial incision is typically limited to $2-3 \mathrm{~cm}$. Access into the peritoneal cavity is then established. We use a Veress needle followed by an AirSeal port (CONMED, Utica NY). Pneumoperitoneum is established and set between 10-15 mmHg. A camera is placed through the insufflation port and three $8 \mathrm{~mm}$ robotic ports are then placed under direct visualization. The ports are placed directly through the fascia on the contralateral side of the intended DIEP flap on a line connecting the anterior axillary line and the anterior superior iliac spine (ASIS). The most cranial port is near the costal margin while the most caudal port is near the ASIS. The middle port is equidistant between the superior and inferior ports. Ports should be placed lateral to the semilunar line to maximize the distance for dissecting out the pedicle (Figure 3). The Da Vinci surgical robot is placed on the ipsilateral flap side of the patient at 90 degrees and the arms are docked in the standard fashion. The operating surgeon is at the console and monopolar scissors and bipolar graspers are used to dissect out the pedicle. The inferior epigastric vessels are seen just superficial to the peritoneal lining. The peritoneum is opened sharply near the origin of the pedicle at the external iliac vessels. The dissection will proceed cephalad until the fascial defect is encountered 


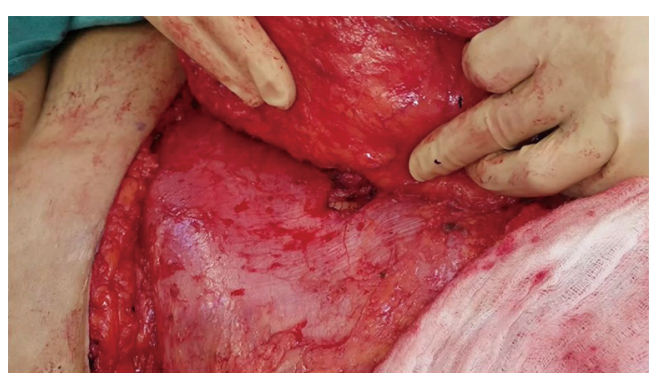

Figure 4 The RoboDIEP fascial incision in typically between 2$3 \mathrm{~cm}$.

from the perforator dissection. Gas will leak from the fascial opening and this is controlled by applying a moist lap pad with gentle pressure. After the pedicle is completely dissected the pedicle can be clipped and divided and then removed through the fascial perforator defect. A barbed suture is then passed through a port and used to close the posterior sheath robotically. The pneumoperitoneum pressure is decreased to $8 \mathrm{mmHg}$ to decrease the tension on the closure of the posterior sheath.

Either a Da Vinci Si or Xi system can be used; however, the $\mathrm{Xi}$ is preferred as the arms are on a boom that can be rotated around a patient without moving the base. The ability to move the arms without moving the base is essential when performing bilateral reconstructions. At this point the flap is taken to the chest and the fascial incisions are closed externally with figure of eight sutures. The remainder of the surgery proceeds as a routine DIEP.

In our early experience we have limited the fascial incision to approximately $2-3 \mathrm{~cm}$ (Figure 4). This reduced fascial incision has reduced post-operative pain, length of stay, and improved overall recovery. Long-term outcomes will need to be assessed but we postulate the decreased fascial incision will certainly also lead to decreased hernia and muscular bulging.

\section{Robotic microsurgery}

The unique features of the robotic system such as complete tremor elimination, 5:1 motion scaling, 10× magnification, and high-dimensional optics are very attractive options for microsurgery and super-microsurgery. Microsurgeons are often operating in a confined space and at difficult angles. The robotic setup allows the microsurgeon to be operating at the console in an ergonomic position. There are currently three applications being used for robotic microsurgery: robotic microsurgery for use in trans-oral reconstruction, robotic micro-neural surgery in brachial plexus reconstruction and robotic lymphovenous bypasses for lymphedema surgery.

The first robotic microvascular anastomosis was performed by Selber in 2010 who published a case series on trans-oral robotic reconstruction of oropharyngeal defects (62). Five patients had reconstruction with either an anterolateral thigh (ALT) or radial forearm free flap. The mandibles were intact and the facial artery was used for the recipient artery and all were performed with a robotic approach. There was a $100 \%$ free flap success rate, no conversion to the traditional hand-sewn technique and no major complications. The access to the facial artery was noted to be difficult due to its course posterior to the hypoglossal nerve and sometimes behind the mandible making the robotic approach favorable compared to the traditional open approach. This was followed by Song et al. who also used robotic microvascular surgery to complete a head and neck reconstruction using a radial forearm flap anastomosed to the facial artery to reconstruct a defect after a tonsillar tumor was removed (63). Both surgeons have highlighted the ability for robotic microsurgery to facilitate microsurgery within a narrow space.

The robotic technique has proved useful for both dissection of peripheral nerve tumors and for nerve repairs (64). Robotic surgery has been used in microneural and brachial plexus surgery $(65,66)$. Using the robotic technique in brachial plexus surgery avoids a long incision and subsequent dissection. The routine use of minimally invasive robotic surgery could eventually enable earlier diagnosis and treatment for brachial plexus injuries (65).

The use of lymphovenous bypass was first described by O'Brien et al. in 1977 in dogs as a means to improve lymphedema (67). However, it took decades for supermicrosurgical techniques and instrument improvements to enable lymphovenous bypasses to come into the armamentarium of microsurgeons. Koshima led the way in the field of super-microsurgery, which is performing anastomoses on calibers of $0.3-0.6 \mathrm{~mm}$, enabling the surgical treatment of lymphedema with lymphovenous bypasses (68). Lymphovenous bypasses are typically performed in an end-to-end fashion using 11-0 or 12-0 nylon sutures with a 50- $\mu \mathrm{m}$ needle (69). These anastomoses challenge and can even surpass the limits of human precision. Even a subtle tremor is exploited by the extreme magnification. The lack of any tremor at all in the robot is 
especially useful in super-microsurgery. Indocyanine green angiography is often used when mapping and planning lymphovenous anastomoses and to prove patency (70). The robotic platform allows facile transitioning between nearinfrared and normal bright field vision which adds another significant advantage. The senior author has used the Da Vinci robotic system to perform many lymphovenous anastomoses successfully and has found the benefits of the robotic system to be highlighted in the techniques required for super-microsurgery.

\section{Putting it all together in a single operation from mastectomy to microsurgery}

We now have all of the elements to offer patients a completely minimally invasive approach to breast reconstruction. A patient could have a robotic nipplesparing mastectomy, followed by a robotic DIEP reconstruction with a robotic microsurgical anastomosis. The patient could even have robotic lymphovenous bypass to address lymphedema that could have arisen after an axillary dissection. This type of total robotic approach both maximizes utilization of the robotic system, as well as the benefit to the patient.

\section{Conclusion}

Robotic approaches to breast reconstruction offer more than just minimally invasive approaches. Microsurgical and super-microsurgery benefits are maximized by robotic technology. We are now able to offer women a completely robotic approach to breast reconstruction.

\section{Acknowledgments}

Funding: None.

\section{Footnote}

Provenance and Peer Review: This article was commissioned by the Guest Editors (Charles E Butler, Carrie Chu, and Margaret Roubaud) for the series "New Frontiers in Breast Reconstruction" published in Gland Surgery. The article was sent for external peer review organized by the Guest Editors and the editorial office.

Conflicts of Interest: Both authors have completed the ICMJE uniform disclosure form (available at http://dx.doi. org/10.21037/gs-20-248). The series "New Frontiers in Breast Reconstruction" was commissioned by the editorial office without any funding or sponsorship. The authors have no other conflicts of interest to declare.

Ethical Statement: The authors are accountable for all aspects of the work in ensuring that questions related to the accuracy or integrity of any part of the work are appropriately investigated and resolved.

Open Access Statement: This is an Open Access article distributed in accordance with the Creative Commons Attribution-NonCommercial-NoDerivs 4.0 International License (CC BY-NC-ND 4.0), which permits the noncommercial replication and distribution of the article with the strict proviso that no changes or edits are made and the original work is properly cited (including links to both the formal publication through the relevant DOI and the license). See: https://creativecommons.org/licenses/by-nc-nd/4.0/.

\section{References}

1. Satava RM. Surgical robotics: the early chronicles: a personal historical perspective. Surg Laparosc Endosc Percutan Tech 2002;12:6-16.

2. Abdul-Muhsin H, Patel V. History of robotic surgery. In: $\mathrm{Kim} \mathrm{CH}$ (ed) Robotics in general surgery. Springer, New York. 2014:3-8.

3. Kwoh YS, Hou J, Jonckheere EA, et al. A robot with improved absolute positioning accuracy for CT guided stereotactic brain surgery. IEEE Trans Biomed Eng 1988;35:153-60.

4. Davies BL, Hibberd RD, Ng WS, et al. The development of a surgeon robot for prostatectomies. Proc Inst Mech Eng H 1991;205:35-8.

5. Leal Ghezzi T, Campos Corleta O. 30 Years of Robotic Surgery. World J Surg 2016;40:2550-7.

6. Hagen ME SH, Curet MJ Introduction to the robotic system. In: Kim CH, editor. Robotics in general surgery. Springer, New York; 2014:9-16.

7. van Mulken TJM, Boymans C, Schols RM, et al. Preclinical Experience Using a New Robotic System Created for Microsurgery. Plast Reconstr Surg 2018;142:1367-76.

8. Madden JL, Kandalaft S, Bourque RA. Modified radical mastectomy. Ann Surg 1972;175:624-34.

9. Jones C, Lancaster R. Evolution of Operative Technique for Mastectomy. Surg Clin North Am 2018;98:835-44. 
10. Medina-Franco H, Vasconez LO, Fix RJ, et al. Factors associated with local recurrence after skin-sparing mastectomy and immediate breast reconstruction for invasive breast cancer. Ann Surg 2002;235:814-9.

11. Agrawal A, Grewal M, Sibbering DM, et al. Surgical and oncological outcome after skin-sparing mastectomy and immediate breast reconstruction. Clin Breast Cancer 2013;13:478-81.

12. Kroll SS, Khoo A, Singletary SE, et al. Local recurrence risk after skin-sparing and conventional mastectomy: a 6-year follow-up. Plast Reconstr Surg 1999;104:421-5.

13. de Alcantara Filho P, Capko D, Barry JM, et al. Nipplesparing mastectomy for breast cancer and risk-reducing surgery: the Memorial Sloan-Kettering Cancer Center experience. Ann Surg Oncol 2011;18:3117-22.

14. Gerber B, Krause A, Dieterich M, et al. The oncological safety of skin sparing mastectomy with conservation of the nipple-areola complex and autologous reconstruction: an extended follow-up study. Ann Surg 2009;249:461-8.

15. Orzalesi L, Casella D, Santi C, et al. Nipple sparing mastectomy: Surgical and oncological outcomes from a national multicentric registry with 913 patients (1006 cases) over a six year period. Breast 2016;25:75-81.

16. De La Cruz L, Moody AM, Tappy EE, et al. Overall Survival, Disease-Free Survival, Local Recurrence, and Nipple-Areolar Recurrence in the Setting of NippleSparing Mastectomy: A Meta-Analysis and Systematic Review. Ann Surg Oncol 2015;22:3241-9.

17. Wei CH, Scott AM, Price AN, et al. Psychosocial and Sexual Well-Being Following Nipple-Sparing Mastectomy and Reconstruction. Breast J 2016;22:10-7.

18. Satteson ES, Brown BJ, Nahabedian MY. Nippleareolar complex reconstruction and patient satisfaction: a systematic review and meta-analysis. Gland Surg 2017;6:4-13.

19. Wijayanayagam A, Kumar AS, Foster RD, et al. Optimizing the total skin-sparing mastectomy. Arch Surg 2008;143:38-45; discussion 45.

20. Garwood ER, Moore D, Ewing C, et al. Total skin-sparing mastectomy: complications and local recurrence rates in 2 cohorts of patients. Ann Surg 2009;249:26-32.

21. Donovan CA, Harit AP, Chung A, et al. Oncological and Surgical Outcomes After Nipple-Sparing Mastectomy: Do Incisions Matter? Ann Surg Oncol 2016;23:3226-31.

22. Son SK, Kim JH, Bae JS, et al. Surgical safety and oncologic effectiveness in robotic versus conventional open thyroidectomy in thyroid cancer: a systematic review and meta-analysis. Ann Surg Oncol 2015;22:3022-32.
23. Rinaldi V, Pagani D, Torretta S, et al. Transoral robotic surgery in the management of head and neck tumours. Ecancermedicalscience 2013;7:359.

24. Leff DR, Vashisht R, Yongue G, et al. Endoscopic breast surgery: where are we now and what might the future hold for video-assisted breast surgery? Breast Cancer Res Treat 2011;125:607-25.

25. Tukenmez M, Ozden BC, Agcaoglu O, et al. Videoendoscopic single-port nipple-sparing mastectomy and immediate reconstruction. J Laparoendosc Adv Surg Tech A 2014;24:77-82.

26. Lai HW, Chen ST, Chen DR, et al. Current Trends in and Indications for Endoscopy-Assisted Breast Surgery for Breast Cancer: Results from a Six-Year Study Conducted by the Taiwan Endoscopic Breast Surgery Cooperative Group. PLoS One 2016;11:e0150310.

27. Kaouk JH, Haber GP, Autorino R, et al. A novel robotic system for single-port urologic surgery: first clinical investigation. Eur Urol 2014;66:1033-43.

28. Badani KK, Bhandari A, Tewari A, et al. Comparison of two-dimensional and three-dimensional suturing: is there a difference in a robotic surgery setting? J Endourol 2005;19:1212-5.

29. Sakamoto N, Fukuma E, Higa K, et al. Early results of an endoscopic nipple-sparing mastectomy for breast cancer. Indian J Surg Oncol 2010;1:232-9.

30. Toesca A, Peradze N, Galimberti V, et al. Robotic Nipplesparing Mastectomy and Immediate Breast Reconstruction With Implant: First Report of Surgical Technique. Ann Surg 2017;266:e28-e30.

31. Sarfati B, Honart JF, Leymarie N, et al. Roboticassisted Nipple Sparing Mastectomy: A feasibility study on cadaveric models. J Plast Reconstr Aesthet Surg 2016;69:1571-2.

32. Toesca A, Peradze N, Manconi A, et al. Robotic nipplesparing mastectomy for the treatment of breast cancer: Feasibility and safety study. Breast 2017;31:51-6.

33. Mittal AK, Dubey M, Arora M, et al. Anaesthetic consideration for robotic nipple sparing mastectomy. Indian J Anaesth 2017;61:519-21.

34. New Data Show Mastectomies Increased 36 Percent From 2005 to 2013. Content last reviewed February 2016. Agency for Healthcare Research and Quality R, MD. Available online: http://www.ahrq.gov/news/newsroom/ press-releases/2016/mastectomy-sb.html

35. Kummerow KL, Du L, Penson DF, et al. Nationwide trends in mastectomy for early-stage breast cancer. JAMA Surg 2015;150:9-16. 
36. I T. Sopra il mio muovo processo di amputazione della mammilla Gazz Med Ital 1906;67:141-2.

37. Pomel C, Missana MC, Lasser P. Endoscopic harvesting of the latissimus dorsi flap in breast reconstructive surgery. Feasibility study and review of the literature. Ann Chir 2002;127:337-42.

38. Lin CH, Wei FC, Levin LS, et al. Donor-site morbidity comparison between endoscopically assisted and traditional harvest of free latissimus dorsi muscle flap. Plast Reconstr Surg 1999;104:1070-7; quiz 1078.

39. Miller MJ, Robb GL. Endoscopic technique for free flap harvesting. Clin Plast Surg 1995;22:755-73.

40. Fine NA, Orgill DP, Pribaz JJ. Early clinical experience in endoscopic-assisted muscle flap harvest. Ann Plast Surg 1994;33:465-9; discussion 469-72.

41. Van Buskirk ER, Rehnke RD, Montgomery RL, et al. Endoscopic harvest of the latissimus dorsi muscle using the balloon dissection technique. Plast Reconstr Surg 1997;99:899-903; discussion 904-5.

42. Selber JC. Robotic latissimus dorsi muscle harvest. Plast Reconstr Surg 2011;128:88e-90e.

43. Selber JC, Baumann DP, Holsinger FC. Robotic latissimus dorsi muscle harvest: a case series. Plast Reconstr Surg 2012;129:1305-12.

44. Damen TH, Mureau MA, Timman R, et al. The pleasing end result after DIEP flap breast reconstruction: a review of additional operations. J Plast Reconstr Aesthet Surg 2009;62:71-6.

45. Tonseth KA, Hokland BM, Tindholdt TT, et al. Patientreported outcomes after breast reconstruction with deep inferior epigastric perforator flaps. Scand J Plast Reconstr Surg Hand Surg 2007;41:173-7.

46. Tonseth KA, Hokland BM, Tindholdt TT, et al. Quality of life, patient satisfaction and cosmetic outcome after breast reconstruction using DIEP flap or expandable breast implant. J Plast Reconstr Aesthet Surg 2008;61:1188-94.

47. Yueh JH, Slavin SA, Adesiyun T, et al. Patient satisfaction in postmastectomy breast reconstruction: a comparative evaluation of DIEP, TRAM, latissimus flap, and implant techniques. Plast Reconstr Surg 2010;125:1585-95.

48. Damen TH, Timman R, Kunst EH, et al. High satisfaction rates in women after DIEP flap breast reconstruction. J Plast Reconstr Aesthet Surg 2010;63:93-100.

49. Damen TH, Wei W, Mureau MA, et al. Medium-term cost analysis of breast reconstructions in a single Dutch centre: a comparison of implants, implants preceded by tissue expansion, LD transpositions and DIEP flaps. J Plast Reconstr Aesthet Surg 2011;64:1043-53.
50. Liu C, Zhuang Y, Momeni A, et al. Quality of life and patient satisfaction after microsurgical abdominal flap versus staged expander/implant breast reconstruction: a critical study of unilateral immediate breast reconstruction using patient-reported outcomes instrument BREAST-Q. Breast Cancer Res Treat 2014;146:117-26.

51. Thorarinsson A, Frojd V, Kolby L, et al. Long-Term Health-Related Quality of Life after Breast Reconstruction: Comparing 4 Different Methods of Reconstruction. Plast Reconstr Surg Glob Open 2017;5:e1316.

52. Hartrampf CR, Scheflan M, Black PW. Breast reconstruction with a transverse abdominal island flap. Plast Reconstr Surg 1982;69:216-25.

53. Grotting JC. The free abdominoplasty flap for immediate breast reconstruction. Ann Plast Surg 1991;27:351-4.

54. Nahabedian MY, Momen B, Galdino G, et al. Breast Reconstruction with the free TRAM or DIEP flap: patient selection, choice of flap, and outcome. Plast Reconstr Surg 2002;110:466-75; discussion 476-7.

55. Koshima I, Soeda S. Inferior epigastric artery skin flaps without rectus abdominis muscle. Br J Plast Surg 1989;42:645-8.

56. Allen RJ, Treece P. Deep inferior epigastric perforator flap for breast reconstruction. Ann Plast Surg 1994;32:32-8.

57. Blondeel PN. One hundred free DIEP flap breast reconstructions: a personal experience. Br J Plast Surg 1999;52:104-11.

58. Selber JC, Fosnot J, Nelson J, et al. A prospective study comparing the functional impact of SIEA, DIEP, and muscle-sparing free TRAM flaps on the abdominal wall: Part II. Bilateral reconstruction. Plast Reconstr Surg 2010;126:1438-53.

59. Lee BT, Chen C, Nguyen MD, et al. A new classification system for muscle and nerve preservation in DIEP flap breast reconstruction. Microsurgery 2010;30:85-90.

60. Lee KT, Mun GH. Perfusion of the diep flaps: A systematic review with meta-analysis. Microsurgery 2018;38:98-108.

61. Fitzgerald O'Connor E, Rozen WM, Chowdhry M, et al. Preoperative computed tomography angiography for planning DIEP flap breast reconstruction reduces operative time and overall complications. Gland Surg 2016;5:93-8.

62. Selber JC. Transoral robotic reconstruction of oropharyngeal defects: a case series. Plast Reconstr Surg 2010;126:1978-87.

63. Song HG, Yun IS, Lee WJ, et al. Robot-assisted free flap in head and neck reconstruction. Arch Plast Surg 
2013;40:353-8.

64. Nectoux E, Taleb C, Liverneaux P. Nerve repair in telemicrosurgery: an experimental study. J Reconstr Microsurg 2009;25:261-5.

65. Facca S, Hendriks S, Mantovani G, et al. Robot-assisted surgery of the shoulder girdle and brachial plexus. Semin Plast Surg 2014;28:39-44.

66. Tigan L, Miyamoto H, Hendriks S, et al. Interest of telemicrosurgery in peripheral nerve tumors: about a series of seven cases. Chir Main 2014;33:13-6.

67. O'Brien BM, Sykes P, Threlfall GN, et al.

Microlymphaticovenous anastomoses for obstructive

Cite this article as: Bishop SN, Selber JC. Minimally invasive robotic breast reconstruction surgery. Gland Surg 2021;10(1):469478. doi: $10.21037 / \mathrm{gs}-20-248$ lymphedema. Plast Reconstr Surg 1977;60:197-211.

68. Koshima I, Inagawa K, Urushibara K, et al.

Supermicrosurgical lymphaticovenular anastomosis for the treatment of lymphedema in the upper extremities. J Reconstr Microsurg 2000;16:437-42.

69. Chang DW. Lymphaticovenular bypass for lymphedema management in breast cancer patients: a prospective study. Plast Reconstr Surg 2010;126:752-8.

70. Ibrahim AE, Sarhane KA, Selber JC. Robotics in plastic surgery. In: Neligan PC, Gurtner GC, editors. Plastic Surgery: 6-Volume Set. 4th ed. Elsevier; 2018. p. Vol 1. 